\title{
ATMOSPHERIC DISPERSION OF PM10 IN AN URBAN AREA
}

\section{Carmelia Mariana Dragomir ${ }^{1}$, Daniel Eduard Constantin ${ }^{1}$, MirelaVoiculescu ${ }^{1}$, Lucian Puiu Georgescu ${ }^{1}$}

Keywords: PM10, atmospheric pollution, long-term trends.

\begin{abstract}
One way of monitoring the atmospheric pollution is to estimate anthropogenic emissions. This paper presents a study of PM10 emissions in a city SE of Romania (Braila) for the period 2009-2012. PM10 emissions decrease from $304.75 \mathrm{t}$ in 2009 to $78.01 \mathrm{t}$ in 2012. Using data from the Environmental Protection Agency Braila and the METI-LIS dispersion model, four maps were produced in order to estimate the spatial distribution of PM10 emission in each year. Results of dispersion models show that the air quality can change abruptly between points at few meters away. Expectedly, PM10 emissions increase towards the centre of the city centre, are generally higher in the vicinity of busy streets and roads.
\end{abstract}

\section{Introduction}

Air pollution distribution is important for estimating human exposure and environment, but usually sources of contamination are frequently difficult to monitor (Bravo et al., 2012) According to SNAP groups, the three significant contributors to urban air pollution are combustion in energy and transformation industries, waste treatment and disposal and road transport. Modelling urban air pollution is a very complex process since the dispersion is influenced by weather conditions, topographical features and urban structural particularities (Wang et al., 2008; Misra et. al., 2013). Dispersion models provide a tool which, in most cases, is based on the relationship between air quality and meteorological data. Results of several available dispersion models have demonstrated that the horizontal dispersion exceeds the vertical dispersion, but both depend on plume properties and the urban features (Saiers et al., 2003; Huang et al., 2008). Spatial dispersion techniques allow locating the source of pollutants and monitor those areas to reduce the negative effects and to conserve the quality of air (Song et al., 2008). By monitoring the relationships between pollutant emissions and the effects of smog,

${ }^{1}$ University "Dunarea de Jos"of Galati, Faculty of Science and Environment, cdragomir@ugal.ro 
dust, and other harmful airborne pollutants on plant and human life, dispersion soft becomes an important tool can use to ensure that no further pollution occurs. (Zhang et al., 2012a).

Particulate Matter 10 (PM10) are particles with diameters less than or equal to 10 microns and is the general term used for solid particles and liquid droplets in the atmosphere. Generally, particulate matters contain a variety of chemicals usually associated with a number of components, including acids (such as nitrates and sulphates), organic chemicals, metals, dust particles, herbicides but also nutrients such as phosphorus for example (Masitah et al., 2007; Noe et al., 2007). PM10 is a major air pollutant in urban areas, mainly in developing countries, where EU limits for PM10 concentration in ambient air is frequently exceeded (EEA, 2012). PM 10 may result from several of natural and anthropogenic sources, including vehicle exhaust emissions, industrial emission sources, transport, agriculture, and smoke from forest fires. (Saleh et al., 2014). Besides effects on human health and biosphere, particle concentration is important also because of their influence on cloud formation and properties and on radiation budget of the earth-atmosphere system, which in turn may cause changes in the atmospheric circulation, surface temperature and precipitation (Leili et al., 2008).

Maximum accepted values for PM10 in the European Union were implemented on 1 January 2008, based on Directive 2008/50/EC. Maximum values of the annual mean are $40 \mu \mathrm{g} / \mathrm{m}^{3}$ while the short-term maximum value is that the 24-hour average of $50 \mu \mathrm{g} / \mathrm{m}^{3}$ is not exceeded more than 35 times a year. Since many EU countries had difficulties in maintaining the above limitations for PM10, regulations have changed, since PM from natural sources increased (Brunekreef and Maynard, 2008).

In this study we show results of modelling the PM10 dispersion in an urban area taking into account the relationship between air pollutants (particulates matters - PM 10 and meteorological factors (temperature, wind speed, wind direction and atmospheric stability).

\section{Data and method}

The PM10 dataset for 2009 - 2012 comes from the Local Environmental ProtectionAgency. Inventories include estimates of all known atmospheric emissions. Emission estimates are collected into databases which usually contain data on the locations of the sources of emissions, emission measurements, emission factors, capacity, production or activity rates in the various source sectors (energy,industrial processes and product use, agriculture, waste, other), operating conditions, methods of measurement or estimation, etc (EEA, 2013). The European Monitoring and Evaluation Programme (EMEP/EEA Air Pollution Emission Inventory Guidebook) is a reference document systematically organized 11 SNAP 
(Select Nomenclature for Air Pollution) codes in accordance with to the classification of sources of atmospheric pollutants. Data on emissions per SNAP source sector are collected by the local agency and stored into the national database, which are analysed in order to take the best decision for future strategy to improve the air quality.

Emissions can be calculated using the following relationship:

$$
E_{i, j}=A_{i, j} \times F_{i, j},
$$

where $\mathrm{E}$ is the emission time series, $\mathrm{A}$ is the activity rate time series, $\mathrm{FS}_{\mathrm{i}, \mathrm{j}}$ is the sectoral emission factor time series, $\mathrm{i}$ is the sector and $\mathrm{j}$ the pollutant.

The dispersion of PM10 was simulated using the METI-LIS software (Kouchi et al., 2004), a program developed originally by the Japan Ministry of Economy, Trade and Industry (METI, 2006). The METI-LIS, model ver. 2.03, is a Gaussian dispersion model and calculates concentrations in steps of one hour or less. Meteorological data and volume of emitted pollutant are essential input items for dispersion models. Wind direction, wind speed and atmospheric stability have a major contribution on dispersion (Kouchi et al., 2004). METI-LIS uses a dispersion equation for point sources the steady-state Gaussian plume. The origin of the calculation's coordinate system is placed at the ground surface at the base of the stack. The $\mathrm{x}$ axis is positive in the downwind direction, the $\mathrm{y}$ axis is crosswind (normal) to the $\mathrm{x}$ axis, and the $\mathrm{z}$ axis extends vertically. The user-defined calculation points are converted to each source's coordinate system for concentration calculation at each time period. The concentrations calculated for each source at each calculation point are summed to obtain the total concentration produced by the combined source emissions for that time period.

$$
C_{(x, y, z)}=\frac{Q V}{2 \pi u_{S} \sigma_{y} \sigma_{z}} \exp \left[-0.5\left(\frac{y}{\sigma_{y}}\right)^{2}\right](2)
$$

$\mathrm{C}$ : Concentration in the $\mathrm{x}, \mathrm{y}, \mathrm{z}$ directions $\left(\mathrm{m}^{3} / \mathrm{m}^{3}: \mathrm{ppb}, \mathrm{ppm}\right.$, or other units)

Q: Pollutant emission rate $\left(\mathrm{m}_{\mathrm{N}}^{3} / \mathrm{s}\right)^{2}$

$\mathrm{V}$ : Vertical term

$\mathrm{u}_{\mathrm{s}}$ : Mean wind speed at release height $(\mathrm{m} / \mathrm{s})$

$\sigma_{\mathrm{y}}, \sigma_{\mathrm{z}}:$ Dispersion parameters in the lateral and vertical directions (m) 


\section{Results and discussion}

Table 1 presents the PM10 yearly average data per SNAP group. Data are collected by the local agency and stored into the national database,depending on each emission source by sector.

Table 1PM10 local emissions inventory, 2009 - 2012, according to SNAP Group [tonnes]

\begin{tabular}{|l|l|c|c|c|c|}
\hline Group & \multicolumn{1}{|c|}{ SNAP groups } & $\mathbf{2 0 0 9}$ & $\mathbf{2 0 1 0}$ & $\mathbf{2 0 1 1}$ & $\mathbf{2 0 1 2}$ \\
\hline Group 1 & $\begin{array}{l}\text { Combustion in energy and transformation } \\
\text { industries }\end{array}$ & 42.10 & 12.91 & 15.33 & 5.86 \\
\hline Group 2 & Non-industrial combustion plants & 2.31 & 2.66 & 41.96 & 2.93 \\
\hline Group 3 & Combustion in manufacturing industry & 0.17 & 0.56 & 5.51 & 0.08 \\
\hline Group 4 & Production processes & 0.01 & 0.05 & 0.05 & 0.03 \\
\hline Group 5 & $\begin{array}{l}\text { Extraction \& distribution of fossil fuels } \\
\text { and geothermal energy }\end{array}$ & 0.00 & 0.00 & 0.00 & 0.00 \\
\hline Group 6 & Solvent and other product use & 0.00 & 0.00 & 0.00 & 0.00 \\
\hline Group 7 & Road transport & 254.33 & 111.58 & 71.09 & 62.17 \\
\hline Group 8 & Other mobile sources and machinery & 0.53 & 1.43 & 0.90 & 1.24 \\
\hline Group 9 & Waste treatment and disposal & 5.30 & 5.57 & 5.33 & 5.71 \\
\hline Group 10 & Agriculture & 0.00 & 0.00 & 0.00 & 0.00 \\
\hline Group 11 & Other sources and sinks & 0.00 & 0.00 & 0.00 & 0.00 \\
\hline
\end{tabular}

According to SNAP groups the most significant contributors to urban air pollution, in the studied area, are road transport, combustion in energy and transformation industries, waste treatment and disposal and non-industrial combustion plants.

Although agricultural activities are important anthropogenic sources in this area, PM10 pollution is zero, according to questionnaires completed by operators. Zero PM10 can be seen also in relation to Group 5, Extraction and distribution of fossil fuels and geothermal energy, which may be true because these activities are very limited. The most significant PM10 pollution originates from road transportation.

Fig. 1 shows the PM10 yearly contribution from each SNAP source, from 2009 to 2012. The PM10 emissions were calculated on the basis of declarations supplied by operators inventoried.

The main sources of PM10 in this area, according to SNAP classification is Group 1, Combustion in energy and transformation industries, $76.20 \mathrm{t}$ and Group 2, Non-industrial combustion plants, contribute with 49.86 t, to total PM10 emission, 
during the analyzed period. The PM 10 quantity recorded by Group 9, Waste treatment and disposal, was only $21.91 \mathrm{t}$.

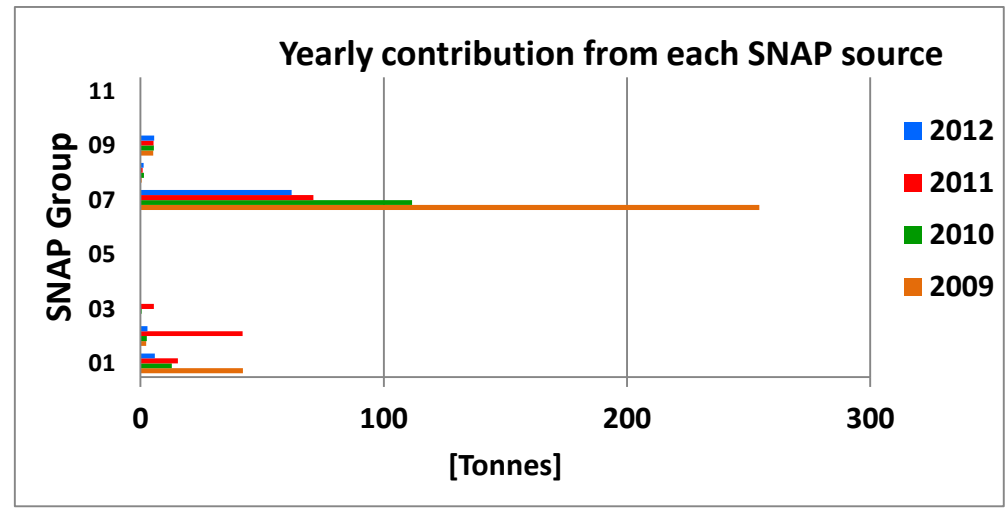

Fig. 1: Yearly contribution from each SNAP source, for 2009 -2012

Fig. 2 shows the PM10 emission evolution in Braila, during theperiod $2009-$ 2012. According to local inventory the main contribution to urban air quality has the SNAP Group 7, Road transport, generated $499.17 \mathrm{t}$ of PM10. Although the period is very short, a descending trend is observed, from $254.33 \mathrm{t}$ in 2009 to 62.17 $t$ in 2012. An important decrease is observed in 2010, when the amount of PM10 was 111.58 t, basically below less than $50 \%$ of the PM10 during the previous year.

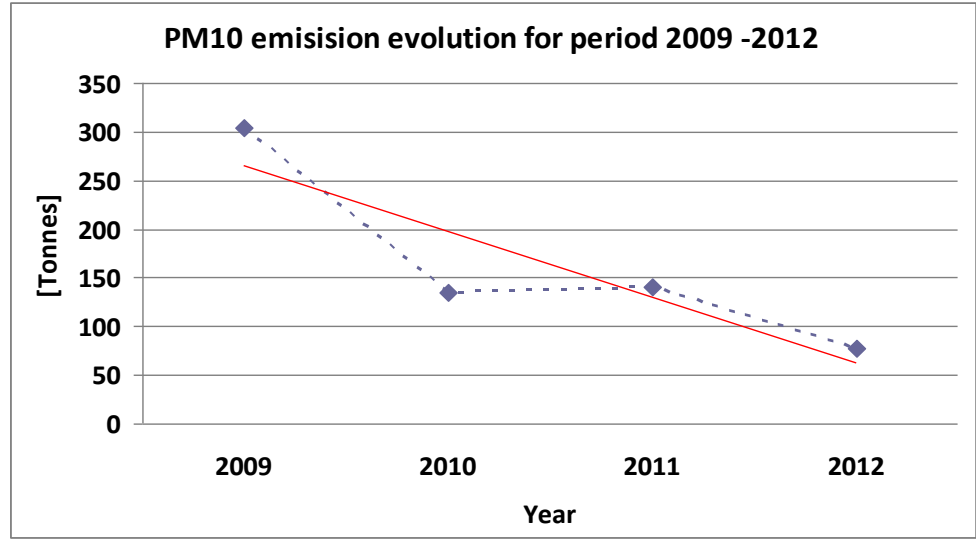

Fig. 2: PM10 emission evolution for period $2009-2012$ 


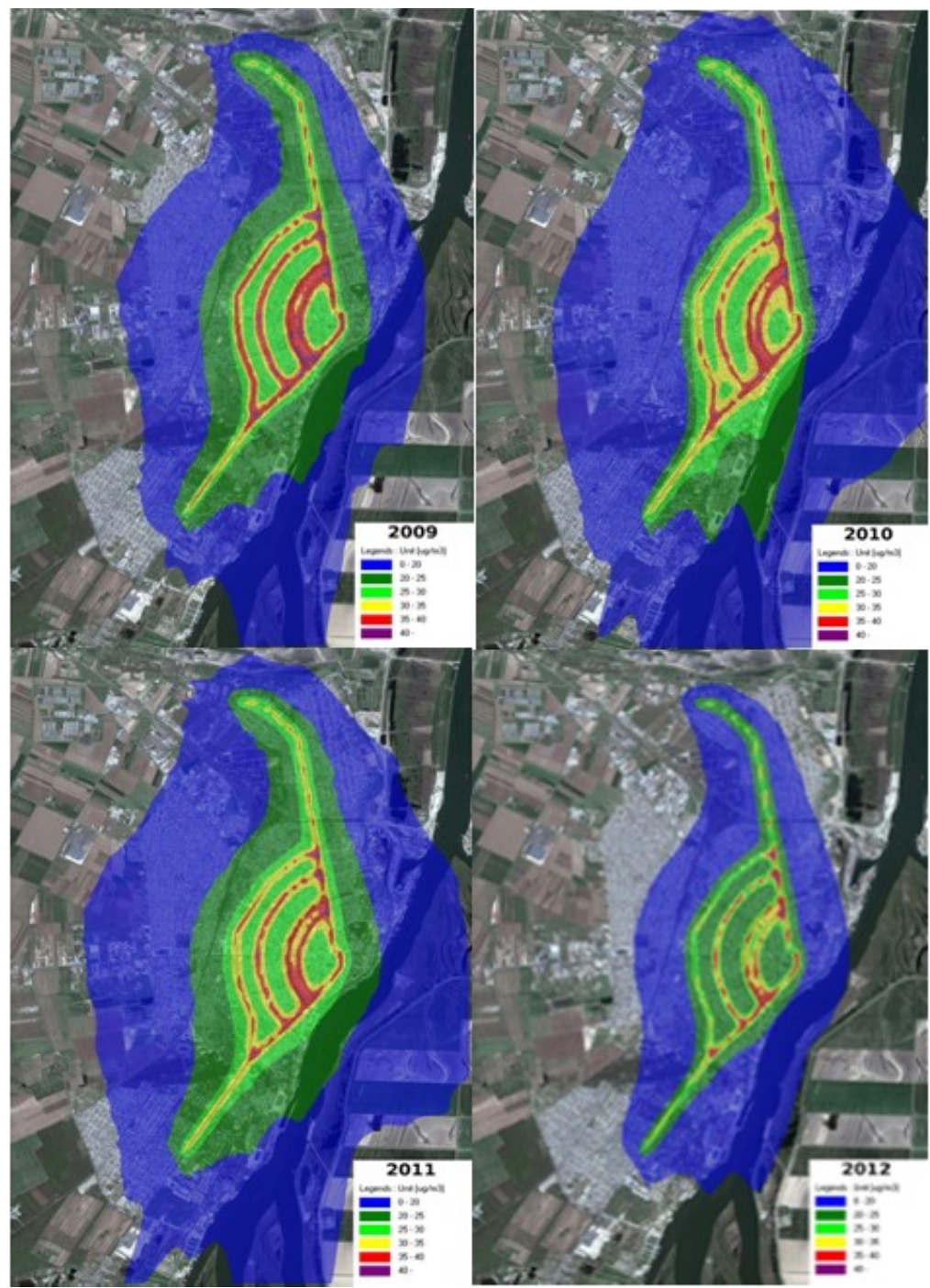

Fig. 3: Dispersion of PM10 for 2009-2012. PM10 concentrations between 0 and $20 \mu \mathrm{g} / \mathrm{m}^{3}$ are shown in blue colour, 20-25 in dark green from 20 to $25 \mu \mathrm{g} / \mathrm{m}^{3}$, in light green $25-30$ $\mu \mathrm{g} / \mathrm{m}^{3}$, in yellow $30-35 \mu \mathrm{g} / \mathrm{m}^{3}$, in red $35-40 \mu \mathrm{g} / \mathrm{m}^{3}$ and violet values over $40 \mu \mathrm{g} / \mathrm{m}^{3}$. Note that the intense green/blue to the SE of the map is due to superposition with the dark colours used in the map

The largest PM10 pollution, i.e. $304.75 \mathrm{t}$ is seen in 2009 (the first year of the analysis), while in 2012 the PM 10 pollution was only $78.01 \mathrm{t}$. The decreasing 
trend of PM10 observed in Braila city can be due to the industrial and economic decline but may be also a consequence of increasing number of car engines equipped with particle filter.

Four maps were created to obtain spatial distribution of annual averages of PM10 emission in Braila. Various scale patterns provides differential influence on air quality dispersion visualization and determine various accuracy of air quality monitoring. Smaller grids determine a more accurate model for typical area while for larger grids it calculates the mean for total grids.

METI-LIS model estimates a distribution of an emission in a relatively large area, such as Braila with a $50 \times 50 \mathrm{~m}$ square spatial grid.METI-LIS was used to produce air pollution dispersion maps for each year, which are shown in fig. 3 .

The highest PM10 concentration is seen along the main streets and in their close vicinity, obviously in connection with the traffic. The largest polluted zones were in the vicinity of busy streets and roads.

In accord with the emission inventory, the PM10 loading gradually decreases. High PM10 concentration is observed along all major roads in 2009 , with some intermittency towards the periphery of the city. These intermittencies are also observed in 2010, 2011 and 2012 and appear, gradually, in the city centre. They are better observed when the PM10 concentration is low, as for instance in 2012. One possibility is that these are associated with meteorological factors, i.e. the wind. On the other hand, a careful look to the maps reveals that spots of PM10 appear mostly near cross-roads and, probably, near traffic lights.

The decrease of PM10 concentration in 2012 can also be observed as an important reduction of the polluted area, which is large, for instance in 2010 and 2011, but small in 2012. This is an effect of meteorological conditions, besides the reduced number of anthropogenic sources. Most likely, a SW wind carries PM10 loading to the south of the city in 2009-2011. An important reduction of PM10 concentration is observed especially at the outskirts of the city, to the West. Streets which were heavily polluted in 2009 tend to be less and less affected by traffic.

\section{Conclusions}

PM10 measurements and annual averages of meteorological parameters were used to map the PM10concentration in an urban area SE of Romania, namely in Braila, using the METI-LIS model, for a period of four years, 2009-2012. Expectedly, METI-LIS maps show that the highest PM10 concentration, thus the most polluted area, relates to point sources associated with traffic.

An important decrease of annual averages of PM10 concentration is observed from 2009 to 2012. PM10 spots still remain and are associated with traffic lights or cross roads. The surface distribution of PM10 is also affected, most likely, by 
meteorological factors but also by reduction of point sources. Measurements support the general decreasing trend shown by calculated emissions at annual level.

AcknowledgementsThe work of Carmelia Mariana Dragomir and Daniel Constantin was supported by Project SOP HRD - PERFORM /159/1.5/S/138963.

\section{References}

Bravo, M., A, Fuentes, M., Zhang, Y., Burr, M.,J., Bell, M.,L., Comparison of exposure estimation methods for air pollutants: ambient monitoring data and regional air quality simulation, Environ Res. , 2012 Jul;116:1-10. doi: 10.1016/ j.envres.2012. 04.008, Epub 2012 May 10.

Brunekreef, B., Maynard, R.L., 2008. A note on the 2008 EU standards for particulate matter.Atmospheric Environment 42, 6425-6430.

European Environment Agency (EEA),Report No.11/2013- The Contribution of transport to air quality (TERM 2013: transport indicators tracking progress towards environmental targets in Europe, ISSN 1725-9177.

European Environment Agency (EEA), Technical report, No 12/2013 EMEP/EEA emission inventory guidebook 2013, Technical guidance to prepare national emission inventories, ISSN 1725-2237.

Huang, Y. H., J. E. Saiers, J. W. Harvey, G. B. Noe, and S. Mylon (2008), Advection, dispersion, and filtration of fine particles within emergent vegetation of the Florida Everglades, Water Resour. Res., 44, W04408, doi:10.1029/2007WR006290.

Kouchi, A., Okabayashi, K., Okamoto, S., Yoshikado, H., Yamamoto, S., Kobayashi, K., Ono, N., Koizumi, M., 2004. Development of a low-rise industrial source dispersion model (METI-LIS model). International Journal of Environment and Pollution 21, 325-338.

Laich, E.J.; Mullen, M.A.; Fields, P.G.; Stella, G.M.; Coad, R.E.; Atkinson, R.D.; Knopes, C. (1995): Emission Projections for Precursors to Atmospheric PM; in: AWMA \& EPA (Hg.): The Emission Inventory: Applications and Improvement; Pittsburgh.

Leili M., NaddafiK.,Nabizadeh R . \&Yunesian M., 2008, The study of TSP and PM10 concentration and their heavy metals content in central area of Tehran ,Iran.Airuality atoms health , 1: 159-166.

Masitah A., Zaini H., and Lee S. K.,(2007), PM10 and Total Suspended Particulates (TSP) Measurements in Various Power Stations, The Malaysian Journal of Analytical Sciences, Vol. 11, No 1: 255-261.

METI. 2006. Low Rise Industrial Source Dispersion Model METI-LIS Model Ver. 2.03, Operation Manual. Ministry of Economy, Trade and Industry.p. 89.

Misra, A., Roorda, M.J., MacLean, H.L.,2013, An integrated modelling approach to estimate urban traffic emissions, Atmospheric Environment 73 (2013) 81-91.

Nepf, H. M., C. G. Mugnier, and R. A. Zavistoski (1997a), The effects of vegetation on longitudinal dispersion, Estuarine Coastal Shelf Sci., 44, 675- 684. 
Noe, G. B., J. W. Harvey, and J. E. Saiers (2007), Characterization of suspended particles in Everglades wetlands, Limnol. Oceanogr., 52, 1166- 1178.

Saiers, J. E., J. W. Harvey, and S. E. Mylon(2003), Surface-water transport of suspended matter through wetland vegetation of the Florida everglades, Geophys. Res. Lett., 30(19), 1987, doi:10.1029/2003GL018132.

Salah A. H. S, Zainab, B., Ghada. H., Mapping Dispersion of Urban Air Particulate Matter Over Kirkuk City Using Geographic Information System, Journal of Environment and Earth Science www.iiste.org ISSN 2224-3216 (Paper) ISSN 22250948 (Online) Vol.4, No.8, 2014 Sansalone, J. J., and S. G. Buchberger (1997), Characterization of solid and metal element distributions in urban highway stormwater, Water Sci. Technol., 36, 155- 160.

Song S. J. , 2008 , A GIS Based Approach to Spatio-Temporal Analysis of Urban Air Quality in Chengdu Plain,The International Achieves of the Photogrammetry, Remote Sensing and Spatial Information Sciences, Vol. 37. Part B7, Beijing.

Wang, G., van den Bosch, F.H.M. and Kuffer, M. (2008) Modelling urban traffic air pollution dispersion. In: ISPRS 2008 :Proceedings of the XXI congress : Silk road for information from imagery : the International Society for Photogrammetry and Remote Sensing, 3-11 July, Beijing, China. Comm. VIII, WG VIII/2.Beijing : ISPRS, 2008. pp. 153-158.

Zhang, Y., Bocquet, M., Mallet, V., Seigneur, C. and Baklanov, A.: 2012a, Real-time air quality forecasting, part $i$ : History, techniques, and current status,Atmospheric Environment 60, $632-655$. 